\title{
Physical Capacity at Cardiac Patients-Tests and Innovative Methods of Rehabilitation
}

\author{
Wasilewski J ${ }^{1 *}$, Wasilewska $A^{1}$, Szulc $\mathbf{N}^{1}$, \\ Ewertowska $\mathbf{P}^{1}$, Zielińska $A^{1}$, Haponiuk- \\ Skwarlińska $\mathbf{J}^{2}$, Gierat-Haponiuk $\mathrm{K}^{1}$ and Ireneusz \\ $\mathbf{H}^{1,2}$ \\ ${ }^{1}$ Chair of Health and Biological Sciences, Gdańsk \\ Academy of Physical Education and Sport, Poland \\ ${ }^{2}$ Department of Pediatric Cardiac Surgery, St. Adalbertus \\ Hospital, Poland \\ *Corresponding author: Wasilewski J, Chair of \\ Health and Biological Sciences, Gdańsk Academy of \\ Physical Education and Sport, ul. Kazimierza Górskiego 1, \\ 80-336 Gdansk, Poland
}

Received: December 30, 2020; Accepted: February 23, 2021; Published: March 02, 2021

\begin{abstract}
Cardiovascular diseases are the most common health problems in highly developed countries. After first rehabilitation stage, patients needs help with long-term recovery process. Physiotherapy for cardiac patients is multifaceted, but it is mainly based on physical capacity. Except physical activity also important are psycho condition and diet.
\end{abstract}

Actually, problems in patients after hospitalization are the lack of motivation to continue training (monotonous exercise) and the fear about pain (recurrence). Patients health during training should be monitored. One of the easiest and most available way is 6-minute walk test. Additionally patients need to have periodic, sensitive tests at clinic (exercise test on treadmill).

New scientific reports suggest extending classical rehabilitation ex. water activities, interval training, and more strength exercise. Variety of possible activity, which are safe for patients, will make rehabilitation more approachable.

Keywords: Efficiency; Physical capacity; Cardiac; Rehabilitation; Training

\section{Introduction}

Cardiovascular diseases, in particular ischemic heart disease and myocardial infarction, are the leading cause of death for people worldwide reported by WHO in 2019 [1]. Thus, the priority should be prevention, reducing the incidence of primary and subsequent diseases, preventing disability and untimely death. Physical activity and diet are the factors that the medical professionals have the most impact on during the cardiology patients treatment [2].

Physical exertion is any movement of the body caused by the work of large muscle groups including energy expenditure. Systematic physical activity has a beneficial effect on the cardiovascular system [3]. Physical activity with energy cost more than $4200 \mathrm{~kJ} /$ week (1000kcal/ week) reduces overall mortality by $30 \%$ and the risk of coronary heart disease decreases from $30 \%$ to $50 \%$ depending on gender [4]. Physical activity of people with cardiovascular diseases is relatively small. Unfortunately, patients are often afraid of undertaking physical activity because of coronary pain [5,6]. According to research of CBOS organization, $51 \%$ of respondents aged $55-64$ and $61 \%$ of those over 65 have not any physical activity in the last year [7]. This is a vicious circle of ischemic heart disease, as increasing sedentary behaviour increases the number of health problems and leads to more serious complications.

20 years of research has proven that people who train regularly have significantly higher levels of physical capacity, their cardiovascular system is more effective, and the incidence of coronary risk is lower [4]. The benefits of regular physical activity include ex. optimal heart rhythm, lower blood pressure values, longer diastolic heart phase, increase maximum minute capacity and cardiac ejection volume, increase number of coronary vessels and it's diameter, increase coronary flow, increase physical capacity, improve quality of life, improve the respiratory system, decrease feelings of anxiety
[8]. Physical activity should be considered as the main preventive and therapeutic method. Physical activity is the best way of prevention, which reduces the use of more radical and costly methods of treatment $[2,9]$.

\section{Physical Activity}

To safely introduce the patient to the rhythm of physical activity, it is necessary to start with basic diagnostic tests (such as blood pressure measurement, blood count, urine test and ECG) and stress test with physical performance assessment. The subjectial interview should include questions about the subject's experience of discomfort during movement and at rest, the occurrence of chest pain, loss of consciousness during exercise, or symptoms of exercise intolerance, such as nausea, vomiting, excessive unusual fatigue and prolonged muscle pain. It corresponds both to individual and supervised selection of the training program by the patients with coronary heart disease $[10,11]$.

Physical activity undertaken by people with multiple risk factors for coronary heart disease or many concomitant diseases should not be too intense, aggravating or performed without the supervision of a physiotherapist and doctor. In order to more accurately arrange the appropriate schedule of activities, the society of cardiology recommends to use the four-stage scale of patients into cardiac groups used in rehabilitation.

Physical activity recommended for people with coronary heart disease is endurance training. It should be done systematically, at least 3 times a week, at an intensity level of at least $60 \%$ of the maximum heart rate (HRmax), and each training should last at least 30 minutes [11]. Endurance training should be complemented by additional strength training. Each workout should be preceded by a warm-up and ended with calming exercises.
Phys Med Rehabil Int - Volume 8 Issue 1 - 2021

ISSN : 2471-0377 | www.austinpublishing group.com

Wasilewski et al. (C) All rights are reserved
Citation: Wasilewski J, Wasilewska A, Szulc N, Ewertowska P, Zielińska A, Haponiuk-Skwarlińska J, et al. Physical Capacity at Cardiac Patients-Tests and Innovative Methods of Rehabilitation. Phys Med Rehabil Int. 2021; 8(1): 1173 
Physical activity recommended for people with coronary heart disease is primarily an activity that patients will perform with pleasure. Lack of regularity will directly affect stagnation and even deterioration of health. It is also recommended to combine and intertwine different sports such as walks, Nordic Walking, cycling, swimming, team games, fitness, circuit training or ballroom dancing. This should be complemented by the physical activity of everyday life that includes climbing stairs instead of taking the elevator, walking or cycling instead of driving, limiting the time spent watching TV or in front of a computer [12].

Although physical activity is desirable in cardiac patients, there are contraindications to the use of physical training, which include unstable angina pectoris, suspected heart attack or acute myocardial infarction, uncontrolled arrhythmias that cause haemodynamic disorders, endocarditis, pericarditis and myocarditis, decompared heart failure, aortic aneurysm, lung disease during respiratory failure, thrombophlebitis, acute febrile diseases, uncompared hypertension at rest (systolic $>180 \mathrm{mmHg}$, diastolic $>110 \mathrm{mmHg}$ ), cerebral focal symptoms in the last 3 months, as well as other conditions requiring intensive patient supervision $[11,12]$.

As a result of systematic physical activity, the physical performance of the body increases. The term "physical capacity" according to the AHA (American Heart Association) is the ability to perform an exercise determined by maximum oxygen absorption, which in practice means the ability to conduct daily activity based on oxygen metabolism. Physical capacity can be divided into aerobic performance for long-term efforts, anaerobic performance for intensive but short-term efforts, and special capacity for a specific type of work performed.

Physical capacity depends on many factors such as the energy capabilities of the body (aerobic energy potential, anaerobic, energy reserves), physical condition (strength, speed, and body weight), diet, level of daily physical activity or mental state. One of the main factors determining physical capacity is the efficiency of the mechanisms of oxygen supply during work, that is, efficient absorption of oxygen from the environment (ventilation, lung capacity), efficient transport of oxygen (blood oxygen capacity, heart minute capacity), the amount of circulating blood and the supply of the tissues (adequate distribution of blood, diffusion of oxygen at the tissue level and disposal of oxygen by tissues). Beyond the objective criteria of physical capacity, the measure of physical capacity may be the amount of work done, the length of the walking distance, the number of floors or steps achieved by the test subject until objective or subjective symptoms of fatigue (Borgs scale) [11,13].

\section{Objective Diagnostic Tests of Physical Capacity}

The assessment of physical capacity can be measured by objective tests and subjective scales. The advantage of every evidence based medicine stress test is the repeatability and possibility of monitoring the heart work, which gives safety. Evaluating physical capacity during a stress test is very important because it allows to be classified according to the New York Heart Association (NYHA). NYHA functional classification takes into account the severity of symptoms and physical activity. Also actually and verify classification is classification of angina severity according to the Canadian Society of Cardiology (CCS) [13].

The 6-minute walking test (6-MWT) is one of the simplest, indirect tests for objective assessment of physical capacity. Made to the standards is a valuable tool for assessing the problem level and to verify progress of treatment at cardiac patients. It involves walking as long as possible (in meters) within 6 minutes [14]. This is a basic diagnostic test used to monitor the progress of cardiac patients in the United States, South America, Africa and Australia [15].

Electrocardiographic stress test is performed on a cycloergometer or trademill and enables indirect measurement of physical performance. To create stress test safety, the supervisor has to monitor some physical and physiology symptoms, which limit the tests, i.e. until the patient achieves high fatigue assessed by the Borgs scale or the onset of symptoms forcing the study to stop (ex. reaches HRmax, arrhythmia). The maximum effort shall be assessed in relation to duration and intensity. The intensity of effort on the cycloergometer is measured in Watts (W) and on the treadmill in Metabolic Equivalents (MET). These tests provide information about the patient's body, not only an electrocardiographic of ischemia, but also in the response of heart rate and blood pressure to exercise. The stress tests are as a valuable tool for assessing physical performance in cardiac rehabilitation clinic [13].

The Bruce protocol is a type of electrocardiographic stress test. The second most popular, immediately after 6-MWT diagnostic test used in monitoring the progress of cardiac rehabilitation. Due to its exactness and safety are often used in Europe and the USA [15]. Carried out according to the original protocol, it is intended for patients with good capacity, so most cardiac laboratories use a modified version with an additional two low levels (from 2,3 MET instead 4,6 MET). This test is performed on a treadmill and lasts about 18 minutes. The patient begins the walk at a low speed $2.7 \mathrm{~km} / \mathrm{h}$ and 0 angle of inclination. Every 3 minutes, the lead increase. The end occurs when the patient achieves a Heart Rate (HR) at the level of HRmax adequate for his age and gender, or faster when the monitored parameters change adversely [16].

The Spiroergometric Exercise Test (CPX) is a reference method for assessing physical performance. In addition to the electrocardiographic test this test measures additionally oxygen absorption, respiratory volume and $\mathrm{CO}_{2}$ excretion. Oxygen absorption at the anaerobic transformation threshold point (AT) is also assessed. In this exercise test, the measure of physical capacity is the maximum oxygen absorption (oxygen ceiling- vo2max, aerobic capacity of the system). In patients with cardiovascular disease, this test is modified and does not consist in achieving $\mathrm{VO}_{2}$ max, but in the absorption of oxygen at the peak of exercise, with a high fatigue corresponding to 7-8 points on 10 grade Borgs scale. In addition to oxygen absorption and $\mathrm{CO}_{2}$ excretion parameters, $\mathrm{CPX}$ gives the ability to assess ventilation - a minute ventilation ratio for $\mathrm{CO}_{2}$ excretion ( $\mathrm{VE} / \mathrm{VCO}_{2}$ slope) and an oxygen efficiency index (OUES) that characterizes the strong of respiratory response to exercise $[13,16]$.

A maximal stress test is a progressive test performed on a cycloergometer or treadmill using a spirometric equipment to the patient's refusal. Determining the basic values of the parameters by 
a)

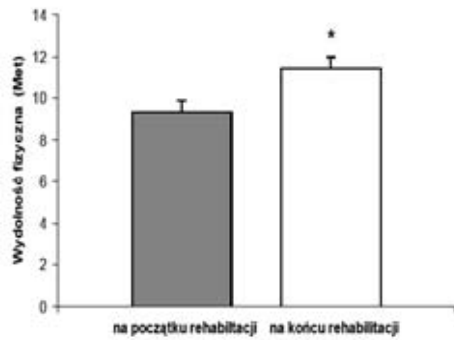

b)
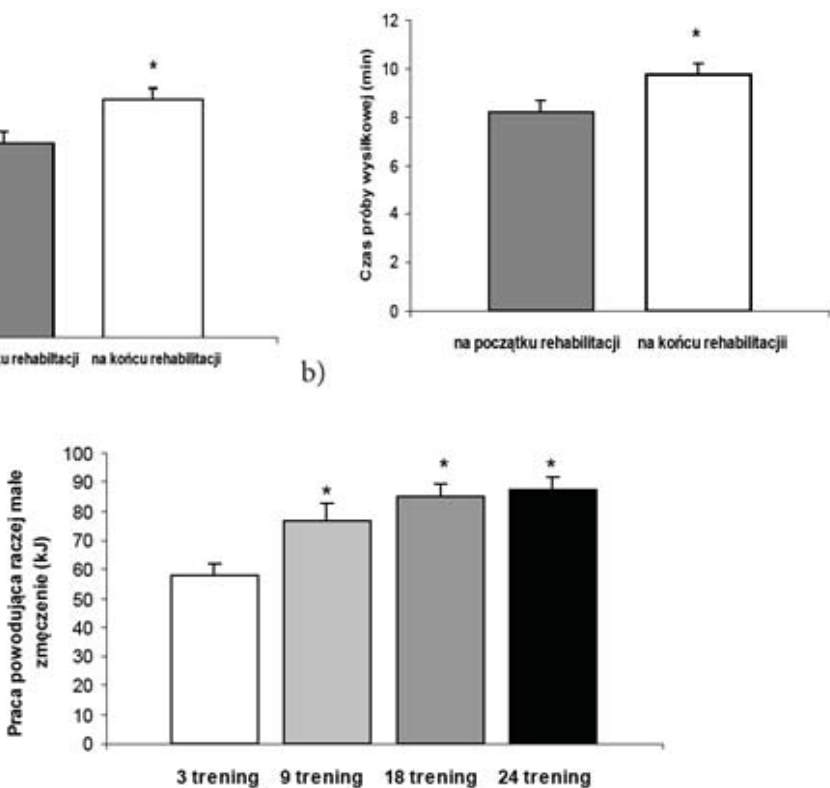

c)

Figure 1: The influence of cardiological outpatient rehabilitation of the physical efficiency of the subjects with a history of myocardial infarction. Results at the beginning and at the end of rehabilitation. A: Efficiency; B: Time span of the effort stress; C: Work inducing relatively small exertion, ${ }^{~} p<0,05$ [19].

this method makes it possible to accurately determine the intensity of physical training and the professional and recreational opportunities of the patient (especially important for young adult patients). At first, heart rate and breathing at rest are measured. Then we proceed to exercise, during which the load increases. This includes further levels for increasing the load, up to the famous "refusal", i.e. the end of the test. The load is increased smoothly and the moment of refusal is individual for the patient. The patient ends the test after reaching his maximum capabilities. During the test, we also study parameters such as maximum power, maximum oxygen uptake, maximum heart rate, heart rate in AT point. The test can be ended faster by the supervisor if symptoms from the group of contraindications will appear $[17,18]$.

Load Echocardiography allows to differentiate diseases of the heart muscle and valves. This test assesses the morphology of the muscle, heart valves, large blood vessels, functions of contraction and diastolic of the heart, disorder of myocardial contractility, flow and pressure in the heart cavities. Making the echocardiographic tests at rest and at the peak of exercise shows changes in heart function during physical exertion with controlled load. Due to the need for additional medical equipment and a specifically trained medical staff, the method is less popular than CPX [13].

Spiroergoechocardiography (CPXE) involves one-time exercise echocardiography and spiroergometric test on a reclining cycloergometer. This allows you to correlate the functional changes evaluated during the imaging test with the dynamics of electrocardiographic, metabolic and ventilation parameters and allows you to objectify the degree of fatigue: achieving AT and RER $\geq 1$ (Ratory Exchange Ratio). The benefits of using this exercise test are a combined cardiac, pulmonary and metabolic evaluation, functional evaluation of the patient's heart function, increasing the prognostic value of exercise echocardiography by attaching spiroergometric parameters [13].
Surface Electromiography (sEMG), which has been used recently to monitor muscle work during exercise in athletes, has recently also attracted interest from cardiac rehabilitation teams. Abnormal heart function may cause peripheral perfusion disorders leading to dysfunction of many organs including muscles [34]. A precise functional and tissue assessment would increase the level of advisability of selected improvement processes. Electromiography is a measurement technique based on the bioelectricity of active muscles. Muscle work closely related to the change in the electrical potentials of cell membranes is detectable on the surface of the skin in an objective and repetitive manner. The signal is collected non-invasively through sensors from properly attached electrodes [31]. However, it should be noted that the place where the electrode is glued on the skin in the area of a given muscle is not accidental. Until now, a big challenge for scientists has been to denoise (neutralize overlapping of noise) the collected sEMG signal from other muscles and tissues. [33] Thanks to the recently created nonlinear noise reduction, the collected signal is more accurate and collected also from lower values [32]. Qualitative and quantitative information on muscle work can be used as a basis for assessing a patient's readiness for a particular type of exercise.

\section{Sulbjective Diagnostic Methods of Physical Capacity}

Physical capacity in the absence of suitable conditions, for screening purposes or taking into account the subjective sensations of patients can be measured using the Borg Scale (10 - or 20 gradual), which consists in determining the patient's fatigue with the appropriate physical load [19]. Buckley's et al. provided interesting conclusions, in which they showed that for the same physical capacity value determined in the stress test, the level of fatigue can vary in subsequent physical training sessions. The Borg scale is not as precise as the stress test, but it is easy and safe, allowing it to be used in all conditions and combined with selected stress tests [20]. The degree of 
physical capacity determined in this way in patients has a therapeutic and initial diagnostic significance. Evaluation in patients undergoing cardiac rehabilitation allows to determine the tense response to physical exertion, bioelectrical activity of the heart, exercise tolerance and physical capacity [21]. The result of the exercise test is the basis for determining the intensity of physical exertion undertaken for example during physical activity at home.

In 2013, the objective and subjective method of assessing physical fitness in people undergoing outpatient cardiac rehabilitation due to a heart attack were compared [19]. The study involved 40 patients - 9 women and 31 men aged 42-82 years who underwent coronary angioplasty surgery due to myocardial infarction and participated in outpatient cardiac rehabilitation. Rehabilitation consisted of 24 onehour sessions 2-3 times a week. Each session consisted of 20 minutes of general fitness exercises, 30 minutes of cycling and 10 minutes of calming exercises. Training on cycloergometers was an interval training with alternating periods of load and rest. They started training with a load of $20 \mathrm{~W}$, which was increased so that each time it caused fatigue 11-12 on the Borg scale. The results are shown in (Figure 1).

\section{Modern Methods of Training in Cardiac Rehabilititation}

Studies clearly show the unquestionable successful cardiac rehabilitation. However, the way to achieve the same goal can be different depending on the region. Each country makes different decisions about the patients' improvement plan. In 2016, Price et al. created a meta-analysis compiling the recommendations of many organizations and societies dealing with cardiac rehabilitation in countries around the world. The summary of training plans for patients showed that the dominant model (due to availability and safety) is endurance training with additional resistance training - a total of 3 times a week on average for up to 60 minutes/training [17].

Technological progress and the availability of rehabilitation tends both patients and medical professionals to seek more effective and diverse forms of rehabilitation. Increased attractiveness and/or availability may lead to the continuation of independent practice at home after the rehabilitation is finished.

Villelabeitia-Jaureguizar et al. In 2019. conducted a randomized clinical trial in which two different exercise protocols were compared: moderate continuous training versus High Intensity Interval Training (HIIT) training, and how it affects the value of Mechanical Performance (MP) in patients with coronary heart disease as part of a cardiac rehabilitation program. A total of 110 men were enrolled in the study - 53 in the continuous training group and 57 in the HIIT training group, and there was no significant difference between groups. Patients were randomly assigned to groups and both workouts were performed on a cyclic ergometer. Training was held 3 times a week for a period of 3 months. The duration of both training protocols per session was 40 minutes, including warm-up and sedation. Exercise intensity was to be maintained by patients at 11 to 13 points on the Borg Scale. In addition, researchers recorded the occurrence of any hazardous incidents on a daily basis in order to be able to verify the safety of using this type of aerobic exercise, which could limit the planning of such protocols for the future. The results of this study indicated that the use of HIIT in low-risk chronic ischemic heart disease patients resulted in greater improvements in $\mathrm{VO}_{2}$ peak and MP with VT1 than with moderate-intensity continuous training. Moreover, only the use of HIIT resulted in a statistically significant increase in MP in VT2 and $\mathrm{VO}_{2}$ peak [22].

Next, in 2018 Hannan et al. conducted a systematic review and meta-analysis of randomized controlled trials to determine whether HIIT training and moderate-intensity continuous training differ from each other in terms of increase in physical performance and whether the duration of training affects the clinical presentation and the list of adverse events. Only studies from the end of July 2017 were taken into account in the review. A total of 17 studies (2 from the USA, 1 from Belgium, 4 from Brazil, 3 from Canada, 1 from Germany, 4 from Norway, 1 from South Korea and 1 from Spain) were included in the meta-analysis. It turned out that HIIT training significantly exceeds continuous training of moderate intensity in increasing physical performance, training lasting from 7 to 12 weeks conducted in accordance with the accepted standards of HIIT training intensity give the greatest effects and that HIIT training is as safe for the participants as continuous moderate intensity training. This is an important systematic review as many countries still consider interval training to be controversial in its use in cardiac patients, and this study shows that HIIT training can be chosen more confidently and safely in cardiac rehabilitation [23].

In a randomized study conducted in 2017 by Elie Fiogbé et al. the Water Aerobic Training (WAT) impact on autonomic heart modulation and body composition in the rehabilitation of patients with coronary artery disease was examined. The study was conducted on 26 men with coronary artery disease randomly assigned to the WAT training group (14 people) and the control group (12 people). The training program consisted of 3 weekly sessions lasting 1 hour on different days of the week over a period of 16 weeks (48 sessions in total).

The training was conducted in a heated pool. Sessions were held together with groups of $3-4$ patients per session, with the intensity of exercise and monotherapy of participants being selected individually. Before each training, the patients' blood pressure and the subjective assessment of exercise perception were measured according to the Borg CR-10 scale. All WATs consisted of a warmup including stretching exercises, walking on the bottom of the pool, and coordination exercises related to breathing exercises. The actual training lasted from 20 to 40 minutes including such activities as walks, running, adaptive games activating the work of the torso, upper and lower limbs. Training intensity was measured by breathing thresholds first (VT1) and second (VT2), with HRTarget between HRVT1 and 10\% below HRVT2. After 24 sessions, the speed of movement in the exercises was increased and the resistance in the limbs was added using dumbbells, balls, ankles, floats etc. Initially, the training lasted 20 minutes and with the HR and BP adapted by the patients, it was gradually increased to 40 minutes. Each training session in the water ended with a 10-minute soothing exercise consisting of breathing and stretching exercises until resting HR and $\mathrm{BP}$ were achieved. In the training group, $48 \mathrm{WAT}$ sessions performed at moderate intensity resulted in a significant improvement in the $\mathrm{HR}$ variability index of patients with coronary artery disease, while 
all the body composition variables remained unchanged. This study suggests that the WAT may be an important therapeutic alternative that should be included in cardiac rehabilitation programs in patients with coronary artery disease, especially those with reduced mobility that impedes proper exercise on land [24].

Next, in 2017 Girold et al. conducted a randomized controlled trial to compare the effect of short-term, but intensive Nordic Walking training with walking without poles in standard cardiac rehabilitation of patients with the history of the acute coronary syndrome and peripheral arterial disease. The study involved 42 men randomly assigned to two groups - Nordic walking training and the control group (walking without poles). Before starting the training protocol, each participant performed a 6-minute walk test (2 times 24 hours apart). The training program lasted 4 weeks and included 5 sessions a week of 45 minutes each. In addition to this training, each patient performed an additional 5 workouts on the cycloergometer, gym and adapted physical activity per week (Monday to Friday) lasting 45 minutes each for a period of 4 weeks. Nordic Walking training and walking without poles covered a distance of 900 meters around the rehabilitation center, the rest of the exercises took place inside the Center. The intensity of the training session was determined in relation to the maximum heart rate obtained by each participant during the exercise test, and the Karvonen method. Each training was preceded by a 10-minute warm-up in order to stimulate the circulatory, respiratory and muscular systems to increased activity. The actual training lasted 45 minutes at the pace adjusted to the training heart rate, and each participant was equipped with a heart rate monitor (Polar FT1), thanks to which they could check on an ongoing basis whether the training takes place at the desired intensity level. After the training, the subjects performed relaxing exercises lasting 5 minutes. At the end of the 4 -week training protocol, each participant retested the 6-minute walk test. After 4 weeks, the Nordic Walking training appeared to be more effective than walking without poles at a distance covered during the 6-minute walk test, therefore it seems to be favorable rehabilitation method of the patients with coronary artery disease or peripheral arteries disease [25].

Prado DML et al. in 2016 focused on ventilation capacity of the coronary heart disease patients with lower aerobic fitness and on the improvement in respiratory capacity among the coronary heart disease patients with initially lower aerobic capacity, in response to aerobic exercise. The study included a total of 123 patients. Before the beginning of the training, the patients performed an exercise test of the maximum cardio-respiratory effort on a treadmill until exhaustion, which enabled them to be divided into 3 exercise groups according to their aerobic fitness status. The training program lasted for 3 months and included 3 workouts a week lasting 60 minutes. Each training session consisted of a 5 - minute warm - up, 30 - 50 minutes of aerobic exercise on the treadmill, and 5 minutes of relaxation exercise. The intensity of aerobic exercise was set at an appropriate heart rate between the Ventilating Anaerobic Threshold (VAT) and the Respiratory Compensation Point (RCP). Each participant was able to achieve the previously set intensity of the aerobic training. The results from this study indicate that coronary heart disease patients with lower levels of aerobic performance had lower respiratory fitness during exercise. Moreover, after 3 months of aerobic training, patients with an initially lower level of aerobic fitness showed greater improvements in respiratory performance through training compared to the other two. Thus, the authors of the study noted that respiratory performance improved with exercise training only in the patients with initially lower levels of respiratory performance [26].

\section{Summarry}

Latest scientific reports suggest extending the standard of the rehabilitation of the cardiology patients with water activities, interval training, and a greater number of strength training sessions, creating a new section of modern methods of cardiology patients' rehabilitation [27]. Training diversification along with the full safety standards of the cardiology patients may cause greater self-discipline among patients to continue training after discharge. Next, another advantage is a comparable level of effectiveness. An excellent transition stage in terms of monitoring patients after discharge is an increasingly popular hybrid rehabilitation. It consists of performing exercises at home with a device monitoring the basic life parameters, which are monitored real-time in the Medical Center by a doctor or physiotherapist [28].

Furthermore, another important aspect of rehabilitation is the selection of the appropriate physical performance test, thanks to which we will be able to monitor the progress of patients over many weeks and months. Currently, the standard in cardiology is the exercise test according to Modified Bruce Protocol and 6-minute walk test supplemented with Borg subjective scale. However, spiroergometric exercise tests, such as the Refusal Test, provide much more information about a patient's level of exercise capacity. Thanks to the intensive research in this area, the scope of rehabilitation is safely extended with new training forms. In addition, the Refusal Test enables more targeted, individual recommendations for patients resulting in the less restrictive recommendations.

The rehabilitation of the cardiology patients should not only focus on a purely physical aspect of rehabilitation, which is the improvement of physical performance, but also on mental well-being. Motivation to move, live, cooperate and the motivation for professional work, are important elements that may determine the final success of the entire recovery process. The authors of the following work, seeing the development of cardiac rehabilitation, would like to emphasize that its complexity also affects the quality of life and mental comfort $[29,30]$.

\section{Conclusions}

- $\quad$ There are modern diagnostic methods that enable precise assessment of the physical activity capability in patients presented with cardiological history.

- The use of modern diagnostic methods in the rehabilitation of cardiology patients enables most favourable choice and use of rehabilitation basing on physical performance and individual capabilities of patients.

\section{References}

1. World Health Organization report. "The top 10 causes of death". 2020.

2. Ziółkowski M, Kubica A, Sinkiewicz W, Maciejewski J. Zmniejszenie umieralności na chorobę niedokrwienną serca w Polsce - sukces terapii czy prozdrowotnego stylu życia? Folia Cardiologica Excerpta. 2009; 4: 265-272.

3. Kazmierczak U, Radziminska A, Dzierżanowski M, Bułatowicz L, Strojek K. The benefits of regular physical activity for the eldery. Journal of Education, health and Sport. 2015; 5: 56-68. 
4. Drygas W, Jegier A. Zalecenia dotyczące aktywności ruchowej w profilaktyce chorób układu krążenia. Medical University of Lodz, Poland. 2003; 38: 76-84

5. Piotrowicz R, Wolszakiewicz J. Choroba niedokrwienna serca. Aktywność fizyczna. Poradnik dla pacjenta. Kreo. 2014: 11-12.

6. Podolec $P$. Wdrożenie rehabilitacji ruchowej $\mathrm{w}$ ramach prewencji utraty zdolności do pracy z powodu chorób sercowo-naczyniowych, wśród mieszkańców województwa małopolskiego w wieku 36-55 lat. Program na lata 2018 - 2021 z perspektywą kontynuacji. Samorząd Wojewódźtwa Małopolskiego. 2017; 4-6.

7. Centrum Badania Opinii Społecznej.

8. Cieślik B. Fizyczne i psychologiczne efekty rehabilitacji kardiologicznejprzegląd piśmiennictwa. Inżynieria Biomedyczna. 2016; 22: 71-97.

9. Medis S, Puska P, Norrving B. Global Atlas on cardiovascular disease prevention and control. WHO. 2011; 164.

10. Redakcja Folia Cardiologica Excerpta. Aktywność ruchowa w pierwotne prewencji choroby niedokrwiennej serca. Folia Cardiologica. 2004; 11: A46-A48.

11. Piotrowicz R, Jegier A, Szalewska D, Wolszakiewicz J, Piotrowicz E. Stanowisko Ekspertów Sekcji Rehabilitacji Kardiologicznej i Fizjologii Wysiłku Polskiego Towarzystwa Kardiologicznego. AsteriaMed. 2017.

12. Nowotny J. Podstawy fizjoterapii; podstawy teoretyczne i wybrane aspekty praktyczne. Część 1. KASPER. 2004; 136-137.

13. Smarż K, Jaxa-Chamiec T, Budaj A. Methods of assessing physical capacity in cardiac patients - electrocardiographic, cardio-pulmonary and echocardiographic exercise testing. 2015; 28: 80-83.

14. Beatty AL, Schiller NB, Whooley MA. Six-minute walk test as a prognostic too in stable coronary heart disease: data from the Heart and Soul Study. Intern Med. 2012; 172: 1096-1102.

15. Price KM, Gordon BA, Bird SR, Benson AC. A review of guidelines for cardiac rehabilitation exercise programmers: Is there an international consensus? European Journal of Preventive Cardiology. 2016; 23: 1715-1733.

16. Rybicki J. Testy wysiłkowe w rehabilitacji kardiologicznej. ASPEL. 2018.

17. Yamauchi F, Adachi H, Tomono J, Toyoda A, Iwamatsu K. Effect of a cardiac rehabilitation program on exercise oscillatory ventilation in Japanese patients with heart failure. Heart Vessels. 2016; 31: 1659-1668.

18. Guazzi M, Bandera F, Ozemek C, Systrom D, Arena R. Cardiopulmonary Exercise Testing What Is its Value? Journal of the American College of Cardiology. 2017; 70: 1618-1636.

19. Domka-Jopek E, Kwolek A, Jopek A. The evaluation of physical efficiency with patients in cardiological rehabilitation on an outpatient basis performed with an objective and subjective manner. Uniwersytet Rzeszowski. 2013; 4 $448-460$

20. Buckley JP, Borg GAV. Borg's scales in strength training; from theory to practice in young and older adults. Appl Physiol Nutr Metab. 2011; 36: 682 692.
21. Wielemborek-Musiał K, Marciniak A, Jegier A. Blood pressure response to physical activity of the males suffering from ischemic heart disease during an ambulatory cardiac rehabilitation program. Folia Cardiologica Excerpta. 2005; 12: 811-819.

22. Villelabeitia-Jaureguizar K, Vicente-Campos D, Berenguel Senen A Hernandez Jimenez V, Ruiz Bautista L, et al. Mechanical efficiency of high versus moderate intensity aerobic exercise in coronary heart disease patients: A randomized clinical trial. Cardiol J. 2019; 26: 130-137.

23. Hannan AL, Hing W, Simas V, Climstein M, Coombes JS. High-intensity interval training versus moderate-intensity continuous training within cardiac rehabilitation: a systematic review and meta-analysis. Open Acces J Sports Med. 2018; 9: 1-17.

24. Fiogbé E, Ferreira R, Sindorf MAG, Tavares SA, de Souza KP. Wate exercise in coronary artery disease patients, effects on heart rate variability, and body composition: A randomized controlled trial. Physiother res Int. 2018; 23: 1713

25. Girold S, Rousseau J, Le Gal M, Coudeyre E, Le Henaff J. Nordic walking versus walking without poles for rehabilitation with cardiovascular disease: Randomized controlled trial. Ann Phys Rehabil Med. 2017; 60: 223-229.

26. Prado DML, Rocco EA, Silva AG, Silva PF, Lazzari JM. The influence of aerobic fitness status on ventilatory efficiency in patients with coronary artery disease. 2015; 70: 46-51.

27. Wang Z, Peng X, Li K, Wu CJ. Effects of combined aerobic and resistance training in patients with heart failure: A meta-analysis of randomized, controlled trials. Nurs Health Sci. 2019; 21: 148-156.

28. Szalewska D, Zielinski P, Tomaszewski J, Kusiak-Kaczmarek M, Lepska L. Effects of outpatient followed by home-based tele monitored cardiac rehabilitation in patients with coronary artery disease. Kardiologia Polska. 2015; 73: 1101-1107

29. Cieślik B. Physical and psychological effects of cardiac rehabilitation - literature review. Acta Bio-Optica et Informatica Medica Inżynieria Biomedyczna. 2016; 22

30. McMahon SR, Ades PA, Thompson PD. The role of cardiac rehabilitation in patients with heart disease. Trends Cardiovasc Med. 2017; 27: 420-425.

31. Mika A. Electric field treatment: yesterday, today and tomorrow. In: Borowicz AM Innowacyjność i tradycja w Fizjoterapii. 2017; 185-193.

32. Sbrollini A, Agostinelli A, Di Nardo F, Maranesi E, Mengarelli A. Evaluation of the Low-Frequency Components in Surface Electromyography. Annu Int Conf IEEE Eng Med Biol Soc. 2016; 3622-3625.

33. Estrada-Petrocelli L, Jane R, Torres A. Neural Respiratroy Drive Estimation in Respiratory sEMG with Cardiac Arrythmias. Annu Int Conf IEEE Eng Med. Biol Soc. 2020; 2748-2751.

34. Węgrzynowska-Teodorczyk K, Siennicka A, Josiak K, Zymlinski R, Kasztura M. Evaluation of Skeletal Muscle function and Effects of Early Rehabilitation During Acute Heart Failure: Rationale and Study Design. Biomed Res Int. 2018; 6982897 